\title{
Utopía dramática. Un acercamiento al teatro mexicano de ciencia ficción
}

Dramatic utopia. An approach to science-fiction Mexican theater

Oscar Juárez-Becerril*

* Investigador independiente Correo-e:

sistemaoskar@hotmail.com

Recibido: 15 de enero de 2020 Aprobado: 1 de mayo de 2020
Resumen: La ciencia ficción propone una realidad alterna basada en el desarrollo de la ciencia. Esta modalidad literaria, en conjunto con el teatro, puede crear mundos ilimitados para el diálogo del hombre con su entorno. Este artículo indaga en las obras "El último juicio, anticipación proletaria", de Germán List Arzubide; "El mundo sin deseo”, de Francisco Navarro Carranza; y “Terraza con jardín infernal”, de Francisco Tario; manifestaciones mexicanas enfocadas en estas temáticas.

Palabras clave: análisis literario; historia literaria; forma y género literario; drama; obra de teatro; teatro nacional; ciencia ficción

Abstract: Science fiction proposes an alternate reality based on the development of science. This literary style, together with theater, can create unlimited worlds for humans to dialogue with their surroundings. The present article enquires on the works: "El último juicio, anticipación proletaria" ["The last judgment, proletarian anticipation”] by Germán List Arzubide; "El mundo sin deseo" [“The world without desire"] by Francisco Navarro Carranza; and "Terraza con jardín infernal" ["Hell garden terrace"] by Francisco Tario; Mexican expressions that focus on these topics.

Keywords: literary analysis; literary history; literary forms and genres; drama theatre; theatrical performances; national theatre; science fiction 
E 1 teatro, amplio entramado de saberes, constituye una simbiosis vital para entender la existencia humana mediante la representación de sus excesos, sus virtudes y, como la literatura misma, marca derroteros que nuestra especie ha transitado y transitará a lo largo de su devenir; perspectivas inconmensurables que surgen de la racionalidad y que no poseen límite.

Para ampliar estas fronteras de la realidad, el ser humano ha imaginado mundos alternos que han encontrado cabida en la ciencia ficción, género cimentado en la aplicación de conceptos o probabilidades científicas. En El universo de la ciencia ficción, Kingsley Amis lo define en los siguientes términos:

Ciencia ficción es aquella forma de narración que versa sobre situaciones que no podrían darse en el mundo que conocemos, pero cuya existencia se funda en cualquier innovación, de origen humano o extraterrestre, planteada en el terreno de la ciencia o de la técnica, o incluso en el de la pseudo-ciencia o la pseudotécnica (1966: 14).

El crítico inglés formula la definición considerando la narrativa, ya que para ese momento no tuvo a su alcance muestras representativas en los ámbitos del teatro o la poesía. No obstante, estos planteamientos funcionan como un punto de partida para conocer la temática que rodea a esta manifestación literaria.

La ciencia ficción amplía la perspectiva del lector con el fin de comprender nuestro devenir, representa proyecciones de la vida humana. Su materia prima, la ciencia, entendida como una de las cúspides de la razón, es sujeta a un cuestionamiento permanente:

La ciencia prosigue develando nuevos caminos. Pero ya no es vista como una panacea universal. La ciencia ficción es una de las encargadas de hacérnoslo ver, de señalar sus errores, sus defectos, sus terribles consecuencias para el mundo; la ciencia ficción como un estímulo más del poder; y la ciencia ficción como un estímulo imaginativo acerca de nosotros mismos. Esperanza y temor en una misma senda creativa (Trujillo Muñoz, 1990: 11).

De esta manera, la característica principal del género proviene de un pacto de lectura cimentado en la hipotética credibilidad de sus conceptos:

Detrás de la ficción narrada en el género, la promesa explícita o implícita de una supuesta garantía científica siempre fue y sigue siendo lo que constituye la especificidad de la Ciencia Ficción: su amparo a la luz y a la sombra del verosímil vertebrado por la particular institución de la tecnociencia (Lorca, 2010: 14).

A manera de bosquejo, y más allá de reconocer que las obras donde aparecen elementos relacionados con la ciencia aparecen prácticamente desde el inicio de la misma literatura, podemos ubicar el primer ejemplo de ciencia ficción moderna en Frankenstein o el moderno Prometeo (1818), de Mary Shelley (1797-1851), texto que ilustra los afanes humanos por desarrollar vida de forma artificial, cuestionando de esta manera los alcances de la tecnología.

En ese mismo siglo surgen narradores trascendentales, como el francés Julio Verne (18281905), que desarrolló su obra durante la segunda mitad del siglo XIX con textos como De la Tierra a la Luna (1865) o Veinte mil leguas de viaje submarino (1870; y el inglés H. G. Wells (18661946), cuyo trabajo funcionó como un gozne entre los siglos XIX y XX mediante las novelas La máquina del tiempo (1895) y La guerra de los mundos (1898).

Es en el siglo XX donde se desarrolla en todo su esplendor este género literario, con artistas que proponen temas como los avances científicos 
y su impacto, los viajes a través del espacio, el contacto extraterrestre o el desarrollo de sociedades armonizadas.

Algunos ejemplos de lo anterior son Más que humano (1953), de Theodore Sturgeon (19181985), novela en la que se plantea un estado evolutivo donde se integran habilidades de diferentes personas; la serie Fundación, escrita por Isaac Asimov (1920-1992), que trata sobre la expansión del ser humano en el espacio y el auge de la robótica; Crónicas marcianas (1950), de Ray Bradbury (1920-2012), quien propone un futuro donde la humanidad coloniza Marte; la saga Dune, de Frank Herbert (1920-1986), que reflexiona acerca de relaciones intergalácticas e incluye temas como la ecología, la religión y la política; ¿Sueñan los androides con ovejas eléctricas? (1968), relato de Phillip K. Dick (1928-1982) que sirvió de base a la película Blade Runner (1982); La mano izquierda de la oscuridad, escrita en 1969 por Ursula K. Le Guin (1929-2018), historia de un planeta donde se han erradicado los problemas sociales derivados de la dualidad sexual; Alas nocturnas (1969), de Robert Silverberg (1935), descripción de ciclos de auge y decadencia de la raza humana; y Neuromante (1984), de William Gibson (1948), texto que sentaría las bases del cyberpunk.

Enfocándonos en el teatro, una de las obras pioneras del género es $R$. U. $R$ (Robots Universales Rossum) de 1920, escrita por el checo Karel Kapek (1890-1938), donde se ahonda en los problemas de la industrialización y se acuña el término 'robot'. ${ }^{1}$ Asimismo, se han puesto en escena obras basadas en la narrativa de ciencia ficción, como Frankenstein o La naranja mecánica.

1 En el artículo "R.U.R. de Čapek: casi un siglo de robots", Daniel Sáiz Lorca comenta sobre el origen del término: "su origen etimológico es checo y deriva de la palabra 'robota' (labor, trabajo) y podría tener también relación con el término 'rob' (esclavo) del antiguo eslavo" (2002: 213).
Panorama general de la Ciencia ficción en MÉXico

Para integrar un panorama general de la ciencia ficción mexicana, propongo hacer un recorrido somero por algunas de sus manifestaciones más importantes, que incluye obras, publicaciones periódicas, premios y antologías.

Obras emblemáticas son el cuento "Sizigias y cuadraturas lunares"2 (1775), escrito por el fraile Manuel Antonio de Rivas (1707 aprox.-?); el relato "México en el año 1970" (1844), de Fósforos Cerillos (pseudónimo de Sebastián Camacho y Zulueta); la novela Querens (1890), de Pedro Castera (1946-1906); el poema "Yo estaba en el espacio" (1905) y la novela corta El donador de almas (1899), de Amado Nervo (18701919); "La conquista de la luna" (1917), de Julio Torri (1889-1970); Eugenia, escrita por Eduardo Urzaiz (1876-1955) en 1919, la primera novela mexicana de ciencia ficción; "Baby H.P.” (1952), de Juan José Arreola (1918-2001); la novela Cristóbal Nonato (1987), de Carlos Fuentes (19282012); y La primera calle de la soledad (1993), de Gerardo Horacio Porcayo (1966), parteaguas del cyberpunk mexicano.

A partir de 1984, el Premio Nacional de Cuento Fantástico y de Ciencia Ficción, organizado por el Gobierno del Estado de Puebla, fue un trampolín para escritores como Mauricio-José Schwarz (1955), José Luis Zárate (1966) y Héctor Chavarría (1950). Además, es necesario mencionar el Premio Kalpa, que ganaron Pepe Rojo (1968), Gerardo Sifuentes (1974) y Alberto Chimal (1970).

Por otro lado, la producción de publicaciones periódicas se remonta a mediados del siglo pasado, con textos que exploran los terrenos de

2 El nombre completo del cuento es "Sizigias y cuadraturas lunares ajustadas al meridiano de Mérida de Yucatán por un anctítona o habitador de la luna, y dirigidas al bachiller don Ambrosio de Echeverría, entonador de kyries funerales en la parroquia de Jesús de dicha ciudad, y al presente profesor de logarítmica en el pueblo de María de la península de Yucatán, para el año del señor de 1775 ". 
la ciencia ficción y que en ocasiones han interactuado con el terror y la fantasía. Algunas muestras son las revistas Crononauta (1964), editada por el colombiano René Rebetez (1933-1999) y el chileno Alejandro Jodorowsky (1929); Umbrales: Revista Mexicana de Ciencia Ficción, Fantasía y Horror; Charrobot, órgano informativo de la Asociación Mexicana de Ciencia Ficción, de Gonzalo Martré (1928); así como los fanzines ${ }^{3}$ Fractal, de José Luis Ramírez y Gerardo Sifuentes; y Goliardos, de H. Pascal. Además, también existen ejemplos de e-zines, ${ }^{4}$ como Otracosa, de Mauricio-José Schwarz, cuyo soporte era el disco de 3.5 pulgadas; y La Langosta Se Ha Posteado, de Gerardo Horacio Porcayo. ${ }^{5}$

A partir de la última década del siglo pasado, se comienzan a preparar antologías dedicadas al género, que tienen la cualidad de ser instrumentos de difusión que condensan temas y autores. Algunos ejemplos son Más allá de lo imaginado (tres volúmenes) 6 (1991) y Sin permiso de Colón: fantasías mexicanas del quinto centenario (1994), de Federico Schaffler (1959); El futuro en llamas. Cuentos clásicos de la ciencia ficción mexicana (1997), de Gabriel Trujillo Muñoz (1958); Silicio en la memoria (1997) y El hombre en las dos puertas ${ }^{7}$ (2002), ambas compiladas por el morelense Gerardo Horacio Porcayo; Visiones periféricas (2001), de Miguel Ángel Fernández Delgado (1967); Los viajeros. 25 años de ciencia ficción mexicana (2010), del escritor y artista gráfico Bernardo Fernández (Bef) (1972); y otras cuyo valor consiste en estar integradas sólo por relatos de mujeres, como el caso de Ginecoides. Las hembras de los androides (2003), de

3 Término definido por el Diccionario de la Real Academia Española como "Revista de escasa tirada y distribución, hecha con pocos medios por aficionados a temas como el cómic, la ciencia ficción, el cine, la música pop, etc." (Real Academia Española, 2017).

4 Fanzines distribuidos por medios electrónicos.

5 Puede accederse a la publicación en el siguiente link: http:// lalangostasehaposteado.blogspot.com/

6 Primera antología de escritores mexicanos de ciencia ficción.

7 Homenaje de escritores mexicanos a la obra del estadounidense Phillip K. Dick.
Jorge Cubría (1950); y La imaginación: La loca de la casa (2015), de Bef, constituida por siete cuentos que pueden ubicarse en la línea de la ficción especulativa, escritos por narradoras mexicanas nacidas entre 1968 y 1979.

Un aspecto por considerar de la ciencia ficción mexicana es su escaso reconocimiento comparado con otras corrientes literarias, dada su poca difusión. Por otro lado, los textos pertenecen casi exclusivamente a la narrativa, cuestión por lo cual nace la inquietud de ahondar en ejemplos desarrollados en la dramaturgia.

Considerando este trabajo como un ejercicio preliminar que funcione como cimiento para continuar con una investigación más amplia, propongo analizar las piezas teatrales "El último juicio, anticipación proletaria”, de Germán List Arzubide; "El mundo sin deseo", de Francisco Navarro Carranza; y "Terraza con jardín infernal”, de Francisco Tario, como ejemplos de obras que desarrollan tópicos relacionados con la ciencia ficción.

\section{Un ATEÍSMO UTÓPICO}

Germán List Arzubide (1898-1998), destacado político, periodista y literato mexicano nacido en la ciudad de Puebla, es mayormente conocido por ser uno de los forjadores del estridentismo junto con otros artistas, como Manuel Maples Arce (1898-1981), Germán Cueto (1893-1975) y Arqueles Vela (1899-1977). El movimiento buscaba romper con los paradigmas de la literatura en boga por medio de la ironía mordaz cimentada en el ensalzamiento de la vida moderna plena de industrialización, maquinismo y velocidad. A su vez, esta corriente mexicana estaba influida por vanguardias, como el futurismo italiano y el ultraísmo español.

Algunas de las manifestaciones literarias más importantes del escritor poblano son El movimiento estridentista (1926), donde con un 
tono desenfadado e irónico asienta algunas de las temáticas claves de esta estética artística; y su poesía, que desarrolla las bases del presente mecánico e impetuoso, representada por poemarios como Esquina (1923), Viajero en el vértice (1927) y Cantos del hombre errante (1970).

El texto que nos ocupa, "El último juicio, anticipación proletaria”, se publicó en 1933 por Ediciones integrales como parte del libro Tres obras del teatro revolucionario, que además contiene las piezas "Las sombras" y "El nuevo diluvio". Se trata de un drama conformado por un solo acto, basado en una supuesta parodia escuchada por List Arzubide estando en la Unión Soviética, donde obreros juzgaban a Dios.

Su primera representación se llevó a cabo el 29 de octubre de 1930 en Xalapa, Veracruz, por trabajadores de la misma ciudad. Al respecto, en la introducción de la obra, el dramaturgo asienta la siguiente anécdota sobre su puesta en escena, en la que se observa lo controvertida e infame que resultaba para la sociedad mexicana de los años treinta:

La representación causó extraordinaria sorpresa y los más fervientes comentarios. A solicitud de la Dirección Educativa Primaria del Estado, se repuso la obra tres días después y, momentos antes de que diera principio la representación, un grupo de miembros de cierta sociedad secreta, armados y en actitud agresiva, asaltó el teatro, pretendiendo impedir el acto, bajo el pretexto de que se hacía burla de una idea religiosa. Los trabajadores que hacían de actores se impusieron, expulsaron a los amenazantes y la obra se pasó por segunda vez (List Arzubide, 1933: 97).

La acotación inicial describe el único espacio que conforma la puesta en escena: una sala oscura donde se llevará a cabo el juicio, que contrasta con el telón rojo, elementos que integran la idea de subversión. Asimismo, la exposición del motivo del juicio la realiza un obrero, enfatizando la crueldad, desigualdad y muerte, todos los males de la humanidad que, en su opinión y en la del gremio que está representando, ha permitido Dios como creador del mundo.

Para poder iniciar con el proceso buscan exhaustivamente a Dios, pero al no encontrarlo físicamente (actitud con la que el autor ironiza sobre su existencia) se presentan algunos de sus retratos, acompañados por los creyentes de cada una de esas figuras para que comparezcan en su nombre. De esta manera, los representantes religiosos exponen sus creencias y la valía de sus dioses, pero éstas se presentan confusas y disímiles, con lo que los personajes se enfrascan en una continua discusión interna sobre la verdad.

En ese momento entra en escena la defensa del proletariado, un intelectual que cuestiona a la figura divina sus atributos de sabiduría, bondad y poder. Además, junto con el presidente de la corte, analiza, con base en criterios lógicos y científicos, algunos conceptos de los devotos, llegando inclusive a su ridiculización. Así, este personaje representa la idea de la razón, un defensor del proletariado basado en el ateísmo.

Los diálogos prosiguen con la disputa permanente de los religiosos que siguen sin ponerse de acuerdo. En esta circunstancia vuelve a aparecer el obrero, quien habla sobre sus compañeros que se han sacrificado por el gremio, los cuales, no obstante su heroísmo, no son considerados dioses, continuando de esta manera con la crítica al dogma expuesta al inicio del juicio:

En Shangai, en Nueva York, en París, en Londres, en todas partes del que a sí mismo se denomina mundo civilizado, los hombres mueren de miseria y de opresión. Y vosotros, los representantes de vuestros dioses, calláis indiferentes a tanto crimen, calláis como vuestros dioses (List Arzubide, 1933: 118).

Los representantes concuerdan finalmente en definir a Dios como un "anhelo espiritual" (List Arzubide, 1933: 121) del hombre y son 
interpelados por el defensor dado lo injusto de su fe, argumentando la existencia de creyentes que deben soportar penalidades que supuestamente les serán recompensadas en otra vida, en contraposición con las personas que controlan la religión, rodeadas por el lujo y el confort.

La liberación simbólica del mundo se da por medio de un viejo y de una mujer, testigos del juicio, personajes que después de escuchar las distintas opiniones caen en cuenta de los engaños de la religión y por tal razón piden integrarse a la lucha de los obreros. Así, como conclusión al juicio de Dios, el presidente asienta tres declaraciones que buscan redimir al hombre de la injusticia:
I. Dios no existe; la idea de Dios ha nacido de los cerebros de los salvajes, incapaces de com- prender la naturaleza y el hombre.
II. La idea de Dios ha servido para encadenar a los trabajadores y entregarlos a la explotación de los capitalistas.
III. Los culpables de que continúe esta fórmu- la criminal son los sacerdotes, cómplices del poder capitalista (List Arzubide, 1933: 129).

Al hacer esta revisión de la obra, advierto que este ejercicio teatral funciona como un documento panfletario donde se plasman los impulsos de un List Arzubide que perteneció al Partido Comunista Mexicano. Así, esta visión encauzada al bienestar social, junto con las aspiraciones del movimiento estridentista al que estaba adherido, integran la motivación ideológica del texto. ${ }^{8}$

El drama, aunque no ahonda en detalles sobre ese futuro contexto ideal, sí propone una

8 Elissa J. Rashkin, en su estudio "La poesía estridentista: vanguardismo y compromiso social”, desarrolla estos vínculos: "Aunque la relación entre vanguardismo estético-cultural y radicalismo social en el siglo XX nos puede parecer casi natural, en realidad las ideologías de la época se expresaban por medio de una multiplicidad de opciones artísticas y literarias. Los futurismos italiano y ruso, asociados con el fascismo y el comunismo respectivamente, ejemplifican la complejidad de esa relación. Ambos movimientos — con sus inevitables diferencias internas - procuraban ir más allá de la expresión artística para transformar la sociedad y la vida cotidiana. No obstante, el hecho de que Mussolini se desasociara de anticipación en la mejora de las condiciones sociales, presentándose así su relación con la ciencia ficción ${ }^{9}$ al encajar dentro de la categoría de utopía, definida por el escritor Gabriel Trujillo Muñoz en Utopías y quimeras. Guía de viaje por los territorios de la ciencia ficción, en los siguientes términos:

La utopía es [...] una lección de vida. Una especulación, sí, desde luego, fantástica y fantasiosa, pero nacida de una realidad humana: de nuestro interés por cambiar el mundo y transformar la vida, de no conformarnos con lo que ya somos, con lo que ya tenemos. Hija de la filosofía griega y madre del Renacimiento y de la Edad Moderna, la utopía concentra el ideal básico de la civilización contemporánea: el progreso (2016: 7$) \cdot{ }^{10}$

De esta forma, "El último juicio, anticipación proletaria" condensa los ideales de List Arzubide basados en el estridentismo como herramienta reaccionaria y en la pugna comunista por la igualdad, en este caso fundamentada en una crítica exacerbada contra la idea de Dios y las religiones convertidas en instrumentos de control. Esta creencia la materializa mediante un drama social que utiliza la utopía para proponer un futuro que habría de llegar en 1953 (veintitrés años después del estreno de la obra), donde el

las propuestas del líder futurista F. T. Marinetti y que el gobierno soviético rechazara el futurismo a favor del realismo socialista, señala la ambigüedad inherente en este tipo de compromiso" (2012: 4).

9 Gonzalo Martré en La ciencia ficción en México (hasta 2002), de 2004, propone este texto como la primera obra de teatro nacional de ciencia ficción.

10 El analista propone como obras fundacionales del género La República (aprox. 380 a. C.), de Platón (427-347 a. C.), y Utopía (1516), de Tomás Moro (1478-1535), de las que nacieron posteriormente textos como Micromegas, (1752) de Voltaire (1694-1798), y algunos trabajos de Julio Verne y H. G. Wells. A su vez, vale la pena mencionar el cuento "La última guerra" (1906), de Amado Nervo, un ejemplo inicial de la presencia de la utopía en la literatura mexicana, en la que los animales se confrontan con los hombres, exigiendo condiciones de igualdad, criticando de esta manera los privilegios de ciertos sectores de la sociedad. 
ateísmo diera paso a un mundo justo y a la conciencia de la humanidad.

\section{ODISEA MARCIANA}

Francisco Navarro Carranza (1902-1967) es un autor prácticamente olvidado por la historia literaria. En Dramaturgia mexicana. Fundación y herencia, de Guillermo Schmidhuber de la Mora, se consignan los siguientes datos biográficos:

Nació en Lagos de Moreno, Jalisco, y es autor de diez obras teatrales. La existencia de este dramaturgo ha pasado casi inadvertida en la historia del teatro mexicano, a excepción de las someras menciones de Nacci, Nomland y Oursler, de que sus libros se enlistan en las bibliografías del teatro mexicano de Lamb y de Mendoza López, y de la publicación en inglés de su pieza La ciudad, en traducción de Knapp Jones (2014: s/n).

"El mundo sin deseo", incluida en El mundo sin deseo y otros dramas, se editó en 1935 por Espasa-Calpe en Madrid, e incluye, además, "La senda obscura", "Trilogía” ("La ciudad”, "El mar", "La montaña”) y "El crepúsculo". Al inicio de la obra se especifica que fue estrenada en el Teatro de la Comedia de La Habana el 19 de junio de 1931 y se trata de una fantasía en tres actos y un prólogo.

El texto inicia con un prólogo que se desarrolla en el espacio exterior e intervienen un ser femenino terrestre y dos entes masculinos, uno marciano y el otro de la Tierra. La mujer busca escapar del amor de su igual y el habitante de Marte la protege, sabiendo de antemano el sentimiento de odio que se puede engendrar en su contraparte humana.

En relación con este planeta vecino, Gabriel Trujillo Muñoz revisa ejemplos de la literatura mexicana de ciencia ficción que se han centrado en la idea de la llegada del hombre a Marte, ${ }^{11}$ haciendo hincapié en el sueño que ha representado en el imaginario popular el volver a comenzar:

Marte. Siempre Marte. La metáfora ideal del futuro que nos espera, de la utopía malograda que pudo ser y no será. Una utopía de la nostalgia: no por un planeta sino por un tiempo de juegos y ensoñaciones. El de nuestra propia infancia (2016: 149).

La acotación inicial del primer acto ubica las acciones en el planeta antes indicado, con casas minimalistas y seres que las habitan vestidos con ropas sencillas. Los nombres de estos individuos se asignan con base en combinaciones de números y letras; el cielo es azulado debido a la poca luz solar. Mediante lo que supone ser una tecnología avanzada, un marciano observa, analiza datos y envía un mensaje. En este sentido, es interesante mencionar que las didascalias describen diseños emparentados con el cubismo, que de esta manera representan la vanguardia en la puesta teatral.

El primer acto de la obra describe el seguimiento que hace un par de marcianos, padre e hijo, sobre la situación de algunos planetas del sistema solar, en específico de la Tierra, que se encuentra en guerra. En este contexto, en una fecha bastante futurista (veinticinco del onceavo mes del año 950 800), arriba por primera vez a Marte una nave terrestre, ocupada por dos hombres y una mujer sobrevivientes de un viaje desafortunado y de los problemas de su mundo. A su vez, se comienza a dar importancia a la figura de la recién llegada, María, quien resulta fascinante para F-2, el joven marciano.

11 Los textos son Yo he estado en Marte (1958), de Narciso Genovese (1911-1982); El mensaje de Fobos (1964), trabajo en conjunto de los hermanos Arturo Gutiérrez Arias (1925-?) e Irene Gutiérrez Arias (1928); Mejicanos en el espacio (1968), escrita por Carlos Olvera (1940-2013); y 2035: Emergency Mission to Mars (1990), de Rodolfo Neri Vela (1952). Cabe destacar que la obra que nos ocupa data de 1931, veintisiete años antes del texto del italiano Genovese. 
En este apartado se expone una crítica marciana enfocada en el poco valor que le otorgan los seres humanos a la vida, a causa, según ellos, de su naturaleza arcaica y salvaje. La mujer platica con A-4 y H-5, el padre y la hermana de F-2, sobre sus terribles recuerdos de la guerra y se compadece de la forma de vida marciana, carente de emoción, a la que según ella le hace falta "arte, amor y dolor" (Navarro Carranza, 1935: 31). En este sentido, se observan las diferencias entre ambas culturas que provocan la crítica mutua.

Es en el acto segundo donde F-2 confiesa a María un sentimiento cercano al deseo, desconocido hasta entonces por su pueblo, sorprendiéndose también de la necesidad de expresarlo por medio del arte, de la manipulación de la roca para plasmarla a ella, objeto de esa pasión.

Mientras se dan tales circunstancias, la paz comienza a trastocarse cuando se avistan naves humanas que se dirigen al planeta rojo, por lo cual María habla sobre la necesidad de defenderse, pero los marcianos no la entienden, dado que se impone su pacifismo. F-2 irrumpe diciendo que el sí está dispuesto a luchar, que ya conoce el odio, situación que desconcierta a su padre, quien entiende en el acto que María ha alterado los valores de su hijo, en el que ahora se imponen sus pasiones sobre la prudencia.

Por otro lado, en el avión cohete ${ }^{12}$ terrestre se da a conocer el motivo del viaje. Kalín, el jefe mongol de la expedición humana, platica con su asesor, Kin-Fú, acerca de sus conquistas en la Tierra y su egoísta necesidad de apoderarse de Marte y de su mujer, María. Es así como los mongoles, dominados por las ansias de poder, capturan a un marciano para usarlo como rehén. En un principio, éste no acepta aclarar las dudas terrestres sobre sus poderosas ofensivas que liquidan

12 Vehículo desarrollado por los seres humanos para acceder al espacio. El texto aporta poca información con respecto a su funcionamiento, destacando algunas de sus características, como poder volar a 5000 kilómetros por hora o estar herméticamente cerrado. a los seres humanos, pero accede al fin tras sufrir la amenaza y la tortura.

El último acto describe un Marte desolado donde Kalín y Kin-Fú conversan sobre el alto costo de su incursión militar. El líder mongol continúa impasible en su idea de conquistar el planeta y, sobre todo, de capturar a María. En ese momento un soldado se acerca para comunicarles que el ejército mongol ha detenido al líder marciano junto con otros combatientes, entre los cuales se encuentra la mujer.

En este acercamiento, Kalín se entera del amor entre María y F-2, y procede a vengarse desterrando a su rival al espacio hasta que llegue su muerte. Los últimos diálogos, junto con la acotación final, describen a una María sumida en el dolor que finge aceptar el amor de Kalín. Cuando éste la conduce a su tienda, ella lo mata y se aleja hasta desaparecer.

A fin de caracterizar a los personajes, podemos decir que Kalín representa la pasión sexual; F-2, la incapacidad de amar; y María, la pasión amorosa. Asimismo, la figura de María cumple dos funciones: oponente y objeto del deseo. En este sentido, está emparentada con otra mujer de la historia, la Malinche, quien actuaba como mediadora de dos mundos, el de los españoles y el de los mexicas, antagonismo que bien puede ser visto como similar al de los terrestres conquistadores y los marcianos conquistados.

Javier Lorca, en su libro Historia de la ciencia ficción, propone tres etapas que ha recorrido el género, basadas en tecnologías que rodean al ser humano, lo imitan o se incorporan a él. En la primera, se da un 'movimiento centrífugo' alrededor de las facultades del individuo mediante ciencia aplicada que las vuelve más eficientes, como en el caso de las naves espaciales. Después, se plantea un 'movimiento orbital', donde se dota a las máquinas de características humanas, ejemplificado por la figura del robot. Finalmente, se formula la idea de un 'movimiento centrípeto', el cual se logra incorporando mejoras en el 
mismo sujeto, siendo el cyborg su prototipo (Lorca, 2010: 155).

De acuerdo con lo antes mencionado, la pieza de Navarro Carranza sería un ejemplo de la primera de estas etapas al presentar un vehículo espacial que hace las veces de extensión del individuo $\mathrm{y}$, aunque no se plantean a detalle las características del artefacto volador, sí sabemos que cumple la función de ampliar las facultades humanas con el fin de acceder a un planeta diferente a la Tierra.

A su vez, dentro de las cuatro categorías contemporáneas del género propuestas por Trujillo Muñoz: la ópera espacial, el cyberpunk, el steampunk y la crítica social, el texto se ubica en la primera de ellas, pues:

podemos contemplar la exploración del espacio exterior en todas sus variantes de contacto con los otros, de concepción filosófica del espacio infinito, de sociedades en mezcolanza creativa o de guerras interminables en las vastedades del porvenir, porque al final de cuentas los humanos seguimos siendo criaturas propensas a recurrir a la violencia para resolver nuestros problemas, para someter al prójimo a nuestro arbitrio o para imponer nuestro dominio territorial en el universo futuro (Trujillo Muñoz, 2016: 44).

De esta manera, "El mundo sin deseo" se presenta como un drama que concentra el tema del viaje en el espacio y el encuentro con seres extraterrestres, con el fin de evidenciar los excesos de la humanidad, representados por el ego exacerbado, el ansia de poder y el deseo reprimido.

\section{EL ABSURDO POSTAPOCALÍPTICO}

Francisco Tario (pseudónimo de Francisco Peláez Vega) nació en la Ciudad de México en 1911 y murió en Madrid el 30 de diciembre de 1977. A lo largo de su vida desarrolló algunas ocupaciones, entre ellas la de futbolista, siendo portero del equipo Asturias, pero también fue astrónomo aficionado, gustaba de tocar el piano y era dueño de un par de cines en el puerto de Acapulco, entre otros oficios y pasatiempos que conjugó con la creación literaria.

En la obra del capitalino vemos la flexibilidad que tuvo para transitar a través de diferentes géneros literarios a lo largo de su quehacer artístico, yendo de los libros de cuentos La noche (1943), Tapioca Inn: mansión para fantasmas (1952) y Una violeta de más (1968), a las novelas Aquí abajo (1943) y Jardín secreto (edición póstuma) (1993), pasando por los aforismos de Equinoccio (1946) y la escritura fragmentaria de Acapulco en el sueño (1951), para llegar finalmente al teatro con El caballo asesinado y otras piezas teatrales (edición póstuma) (1988).

Este último texto fue publicado como parte de la colección Molinos de Viento de la Universidad Autónoma Metropolitana, en colaboración con el Instituto Nacional de Bellas Artes. El volumen incluye, además de "El caballo asesinado", que da nombre al texto, "Terraza con jardín infernal" y "Una soga para Winnie". Sonia Morales, en su artículo "Ruiz Saviñón rescata el teatro de Francisco Tario", cuenta la siguiente anécdota con respecto a su publicación:

Ruiz Saviñón cuenta que Tario mandó quemar estas obras de teatro; pero su hermano, el pintor Antonio Peláez, las guardó, y recientemente la UAM y el INBA hicieron una coedición con ellas, "únicas en el teatro mexicano porque tienen influencia del teatro de humor negro y del absurdo, a pesar de que fueron escritas en los años cincuenta, incluso - creo- fueron hechas antes de que lonesco escribiera Rinoceronte" (1989: s/n).

La pieza "Terraza con jardín infernal", objeto de este análisis, se desarrolla en dos actos y se ambienta en un mundo posterior a una hipotética 
hecatombe nuclear, sin ninguna referencia geográfica específica más que el nombre del hotel: La Lata de Arenques Ahumados.

La acotación inicial, referente a la sala de espera y la terraza, es extensa y bastante descriptiva, por lo que parece más cercana a una narración, con detalles vagos que parecen difícilmente representables. Tal es el caso de la expectación de ciertos personajes, como la señora Walzer: "en espera de un inminente y sentimental acontecimiento", o la descripción del Millonario, "en cierta forma sensacional" (Tario, 2016: 401).

El primer diálogo lo sostiene un par de huéspedes: el señor Leopardi, uno de los últimos sobrevivientes del fin del mundo, y la señora Walzer. El primero refiere los pormenores de la explosión que acabó con la Tierra, la cual aconteció noventa años antes del día de la plática, ${ }^{13}$ un veinticinco de mayo a las seis y media de la mañana. La descripción del cielo colapsado: "Se interrumpió la aurora y sobrevino muy anticipadamente el crepúsculo" (Tario, 2016: 403), junto con el olor a uranio, fueron el preámbulo de la explosión que abrazó todo a su alrededor y del que emergió un mundo consumido: "iUn mar! iUn mar desolado y gris!, cubierto de espantosos ladrillos también grises” (Tario, 2016: 404). Así, el tema del mundo postapocalíptico puede concebirse como una visión de la humanidad producto de los desastres nucleares acontecidos durante la Segunda Guerra Mundial, la cual conoció el escritor mexicano en plenitud de facultades.

La plática continúa con otro elemento importante para comprender a los integrantes del drama, la sorpresa por la llegada al hotel de una mujer embarazada, donde entendemos un poco sobre su morfología y alcances: "¿Pero es que

13 La fecha exacta de escritura de la obra no se tiene clara. Para 1971, fecha de la segunda entrevista de Tario con José Luis Chiverto, menciona: "Vengo trabajando desde hace tiempo en dos piezas de teatro, ya de hecho terminadas, El caballo asesinado y Terraza con jardín infernal" (Tario, 2016: 691). Como cité anteriormente, Ruiz Saviñón habla incluso de su elaboración durante la década de los cincuenta. podemos, en realidad, los plásticos tener una cosa así?" (Tario, 2016: 406).

Otro de los hospedados, denominado Millonario, al escuchar la conversación se queja con la dueña del hotel sobre el pesimismo con el cual se expresan: "¿De qué se trata? ¿De sabotear la industria de los plásticos?" (Tario, 2016: 407). Este personaje también es nombrado señor Wallenstein y el motivo de su encono son sus negocios, ya que funge como presidente de la Trust Plastic Corporation y es heredero universal de la Cell and Similars Company.

En este punto del análisis, es importante mencionar el carácter absurdo de ciertos detalles que se presentan a lo largo de la obra. Uno de ellos es encarnado por el profesor Kurtzer, del que se dice es experto en proyectiles, cuyo único medio para participar en las conversaciones es articular la palabra (interjección) “iPum!”. De él sólo se obtienen muestras mínimas de sapiencia, como cuando anota en una hoja: "iSe ha imantado el caos!” (Tario, 2016: 412), refiriéndose a un cataclismo posterior, relacionado con una fuente difusa de electricidad, protoplasma o desmineralización, que quizá provoque una explosión. Después, el Millonario explica a otro de los personajes, Peterhof, quien ha perdido un ojo y busca el favor de que le consiga uno nuevo, la dinámica de su negocio, que a su vez es la forma de vida del nuevo mundo:

\footnotetext{
La demanda de plásticos y células vivas va en aumento. Nuestros padres de familia se hallan cada día más urgidos de grandes remesas de bebés plásticos. Y los bebés plásticos, consecuentemente, se hallan a su vez urgidos de grandes remesas de células vivas para nutrir su organismo (Tario, 2016: 409).
}

Aunando al tema del absurdo, se da un hecho inverosímil cuando el Millonario asesina, sin sentido, al papá del supuesto bebé que nacerá. Un inspector juzga el acontecimiento y ordena la pena capital, la cual no se puede cumplir dado 
que las balas no funcionan. El Millonario mata al policía de un puñetazo (quien posteriormente, estando en el suelo, continúa interactuando con los personajes) y todos regresan a las actividades que hacían antes.

El doctor del albergue aparece con el recién nacido Basilio Vasilievich Klimin, caballero de unos cuarenta años, quien conoce secretos de los presentes, pero no los recuerda: "Yo les conocí en sueños, viví largas horas con ustedes en sueños; pero ustedes... ino, tal vez ustedes no tengan por qué recordarme! ¿Cómo podrían recordar a cada uno de los infinitos seres que sueñan con ustedes a diario?" (Tario, 2016: 430). Después, los personajes lo reconocen y éste les informa que acaba de morir, acción que desencadena el sonido de energía eléctrica corriendo al lado del telón.

El segundo acto inicia con una acotación que también parece cercana a la narrativa: "alegre mañana de estío [...] claridad casi líquida del aire" (Tario, 2016: 431). Estas aclaraciones para la representación también suman a la sensación de absurdo presente en ciertos diálogos o circunstancias, como la que describe el homicidio del Doctor a manos del señor Wallenstein usando el telefóno: "El Millonario contempla el aparato, $y$, en un rapto de ira, retuerce el cordón sanguinariamente. La voz cesa, percibiéndose un dolorido lamento seguido de un estertor apagado" (Tario, 2016: 434).

Por otro lado, mediante un comentario de la señora Walzer, se comunica la existencia de calidades entre los mismos seres, algunos de los cuales parecen existir en la marginalidad: "soy un plástico de segunda mano, ¿comprende? Ello se explica. Mis padres nunca fueron acaudalados y alguien los engañó inicuamente. Mis padres vivían muy solos y adquirieron esto" (Tario, 2016: 440).

Posteriormente, aparece un grupo contrario al del Millonario, encabezado por Basilio (quien desde el principio del acto aparece con vida, no obstante se haya anunciado su muerte al final del primer apartado), nombrado Hormonas S. A. Así, Vasilievich increpa a Wallenstein sobre la mala calidad de sus productos: "proliferan, pobres en salas, mujeres fermentadas, estériles, seres sin plasma" (Tario, 2016: 448).

Al final de la obra se dan dos hechos importantes; por un lado, la negociación entre Basilio y el Millonario para seguir desarrollando sus negocios, y por otro, el más trascendente, en el que este nuevo mundo parece cerca de sucumbir: "El firmamento se ha enrojecido, se ha vuelto fosforescente y parece próximo a estallar" (Tario, 2016: 453), acción que finalmente se completa junto con el cierre: "El firmamento, como un globo que se desinfla, pierde su último fulgor, y en una suerte de penumbra lunar va cayendo lentamente el telón final" (Tario, 2016: 454).

De acuerdo con lo analizado, existe una relación estrecha de esta pieza dramática con el teatro del absurdo. En una entrevista con José Luis Chiverto, Tario habla sobre los escritores más destacados relacionados con lo fantástico, y afirma: "Decididamente Kafka. En el relato breve Supervielle, y, en el teatro, Ionesco [son], con quien[es] me siento más identificado" (2016: 685). De acuerdo con esta correspondencia, que se materializa en un teatro flexible, David Olguín comenta lo siguiente:

Por desgracia no podemos decir que Ionesco o Beckett leyeron a Tario para fraguar lo mejor del teatro del absurdo. Lo único que podemos afirmar es que Tario, aún con todas sus limitaciones, se apropió de algún modo de la concepción del texto dramático que caracteriza a dichos autores: el texto entendido no como literatura sino simplemente como teatro, como la columna de un espectáculo donde el diálogo posibilita la acción y el juego escénico. En este sentido, Tario hace de la literatura dramática una materia totalmente abierta para el desarrollo de las diversas imaginaciones (directores, 
actores, escenógrafo...) que intervienen en una puesta en escena (1989: 665-666).

De esta forma, mediante circunstancias abstractas emparentadas con el teatro del absurdo, la obra plantea un mundo postapocalíptico habitado por dos tipos de seres, unos orgánicos, producto de células vivas, y los otros, entes de plástico emparentados con androides, los cuales son sojuzgados por empresas que monopolizan insumos necesarios para la sobrevivencia de los habitantes. Además, los personajes viven pensando en la destrucción de su hábitat, lo que le da al texto un matiz de caos permanente.

\section{Nuevo SIGLO}

Aunando a las propuestas revisadas, a partir de 2010 se ha escenificado un mayor número de obras relacionadas con temas propios de la ciencia ficción, algunas de ellas desarrolladas con base en textos narrativos, como el caso de El donador de almas, de Amado Nervo, adaptada por Adrián Chávez en 2019, y otras cuyas influencias inmediatas provienen del arte cinematográfico, como Camino a Fort Collins (2014), de Martín Zapata; ${ }^{14}$ La velocidad del zoom del horizonte, escrita en 2016 por David Gaitán, ${ }^{15}$

14 José Luis Tercero describe de la siguiente manera una de las escenas: "En un bar, a mitad de la carretera de camino a Fort Collins, una mujer baila cadenciosamente sobre una mesa, "you're just like an angel, your skin makes me cry..." reza la canción de Radiohead que se escucha de fondo mientras un hombre solitario contempla extasiado aquel cuadro celestial. Ella dirige una mirada al cielo que pareciera una plegaria y sonríe justo cuando unas luces aparecen en lo alto y la bañan de una sustancia incomprensible. Afuera del establecimiento, la tormenta ruge" (2015).

15 El dramaturgo, quien también funge como actor, la define así: "La historia que contamos con esta obra es profundamente compleja en tanto que las reglas de esta realidad que planteamos no son las que conocemos, entonces, la obra comunica al espectador cómo funciona esta dinámica; quién es humano; quién no es humano; dónde están; qué hacen ahí; qué es lo que ha pasado a lo largo del tiempo de estancia; y qué es lo que han generado las dinámicas de encierro, como resultado de estar ahî" (Perches, 2016). con referencias al cine de Lars von Trier; 2001. Una odisea del espacio, de Kubrick; la novela Solaris, de Stanislaw Lem; y Mulberry, de 2017, en la que Stephanie León ${ }^{16}$ explora los senderos de la ficción científica.

\section{CONCLUSIONES}

La producción de teatro mexicano de ciencia ficción no se puede comparar con la de otros géneros, como la narrativa, que posee una tradición más arraigada. No obstante, existen ejemplos de la incursión de algunos dramaturgos en este género especulativo, que se pregunta constantemente sobre cuestiones trascendentales para el hombre, en escenarios y circunstancias que están plenos de expectativa.

El análisis realizado, considerado dentro de la relativamente escasa labor literaria dedicada a estos temas, difícilmente puede plasmar de manera global los motivos que definen el teatro de ciencia ficción mexicana. Lo que identificamos son textos poseedores de características propias que los hacen diametralmente opuestos entre sí, enriqueciendo de esta manera al género.

"El último juicio, anticipación proletaria”, de Germán List Arzubide, expone un drama social que desarrolla un mundo utópico donde el futuro, basado en el ateísmo, permite la equidad y el desarrollo del ser humano. El drama "El mundo sin deseo", de Francisco Navarro Carranza, retoma la idea de los viajes en el espacio y el contacto con extraterrestres para mostrar los excesos del amor, de la pasión y del ego. Finalmente, el teatro del absurdo que contiene una temática postapocalíptica, semilla del actual cyberpunk, aparece en "Terraza con jardín infernal", de Francisco

16 Indira Cato resume la obra en los siguientes términos: "En esta historia, Tom [...] es un científico desarrollando inyecciones que permitan a los humanos regenerar tejido corporal. Hace una convocatoria para experimentar con un voluntario. La elegida es Beth [...], una astrofísica con carrera frustrada" (Cato, 2017). 
Tario, para enfatizar una crítica a los monopolios que condenan a las personas a vivir dentro de un desconcierto perpetuo.

\section{REFERENCIAS}

Amis, Kingsley (1966), El universo de la ciencia ficción, Madrid, Ciencia Nueva.

Cato, Indira (2017), "'Mulberry': Un viaje al espacio en el Cenart", en Proceso, México, 8 de diciembre de 2017, disponible en: https://www.proceso.com.mx/514185/mulberryun-viaje-al-espacio-en-el-cenart

List Arzubide, Germán (1933), Tres obras del teatro revolucionario, México, Ediciones Integrales.

Lorca, Javier (2010), Historia de la ciencia ficción, Buenos Aires, Capital intelectual.

Martré, Gonzalo (2004), La ciencia ficción en México (hasta 2002), México, Instituto Politécnico Nacional.

Morales, Sonia (1989), "Ruiz Saviñón rescata el teatro de Francisco Tario", en Proceso, México, 16 de septiembre de 1989.

Navarro Carranza, Francisco (1935), El mundo sin deseo y otros dramas, Madrid, Espasa-Calpe.

Olguín, David (1989), "Escenarios, ejercicios, reencuentros", en Obras completas, t. II, Novela, teatro y textos no coleccionados, México, FCE, pp. 664-666.

Perches, Salvador (2016), "iExiste la ciencia ficción teatral mexicana?", en Noticias 22 Digital, México, 21 de julio de 2016, disponible en http://noticias.canal22.org. mx/2016/07/21/existe-la-ciencia-ficcion-teatra/

Rashkin, Elissa J. (2012), "La poesía estridentista: vanguardismo y compromiso social", Intersticios Sociales, núm. 4, pp. 1-30.

Real Academia Española (2017), "fanzine", en Diccionario de la Lengua Española, disponible en: https://dle.rae.es/index. html

Sáiz Lorca, Daniel (2002), "R.U.R. de Capek: casi un siglo de robots", Eslavistica Complutense, vol. 2, pp. 211-218.

Schmidhuber de la Mora, Guillermo (2014), Dramaturgia mexicana. Fundación y Herencia, Alicante, Biblioteca Virtual Miguel de Cervantes, disponible en http://www.cervantesvirtual.com/obra/dramaturgia-mexicana-fundacion-yherencia/

Tario, Francisco (2016), Obras completas II. Novela, teatro y textos no coleccionados, México, FCE.

Tercero, José Luis (2015), "Camino a Fort Collins, teatro mexicano de ciencia ficción", Gaceta Digital UNAM, 3 de febrero de 2015.

Trujillo Muñoz, Gabriel (1990), "Prólogo", en Federico Schaffler, Más allá de lo imaginado. Antología de ciencia ficción mexicana, México, Fondo Editorial Tierra Adentro, pp. 9-15.

Trujillo Muñoz, Gabriel (2016), Utopías y quimeras. Guía de viaje por los territorios de la ciencia ficción, México, Jus.
Oscar Juárez Becerril. Especialista en Literatura Mexicana del siglo XX. Realizó estudios de Ingeniería Civil en la Universidad Autónoma del Estado de México (UAEM), México, y posteriormente cursó la Licenciatura en Lengua y Literaturas Hispánicas en la Universidad Nacional Autónoma de México (UNAM), México, así como la especialización en Literatura Mexicana del Siglo XX en la Universidad Autónoma Metropolitana (UAM), México. Se desempeña como investigador independiente y sus líneas de interés se enfocan en la literatura fantástica, la literatura de ciencia ficción y la literatura popular y tradicional. Entre sus publicaciones encontramos: "El charro negro y las cuevas: relatos del valle de Toluca" (Revista de Literaturas Populares, año XV, núm. 1). 


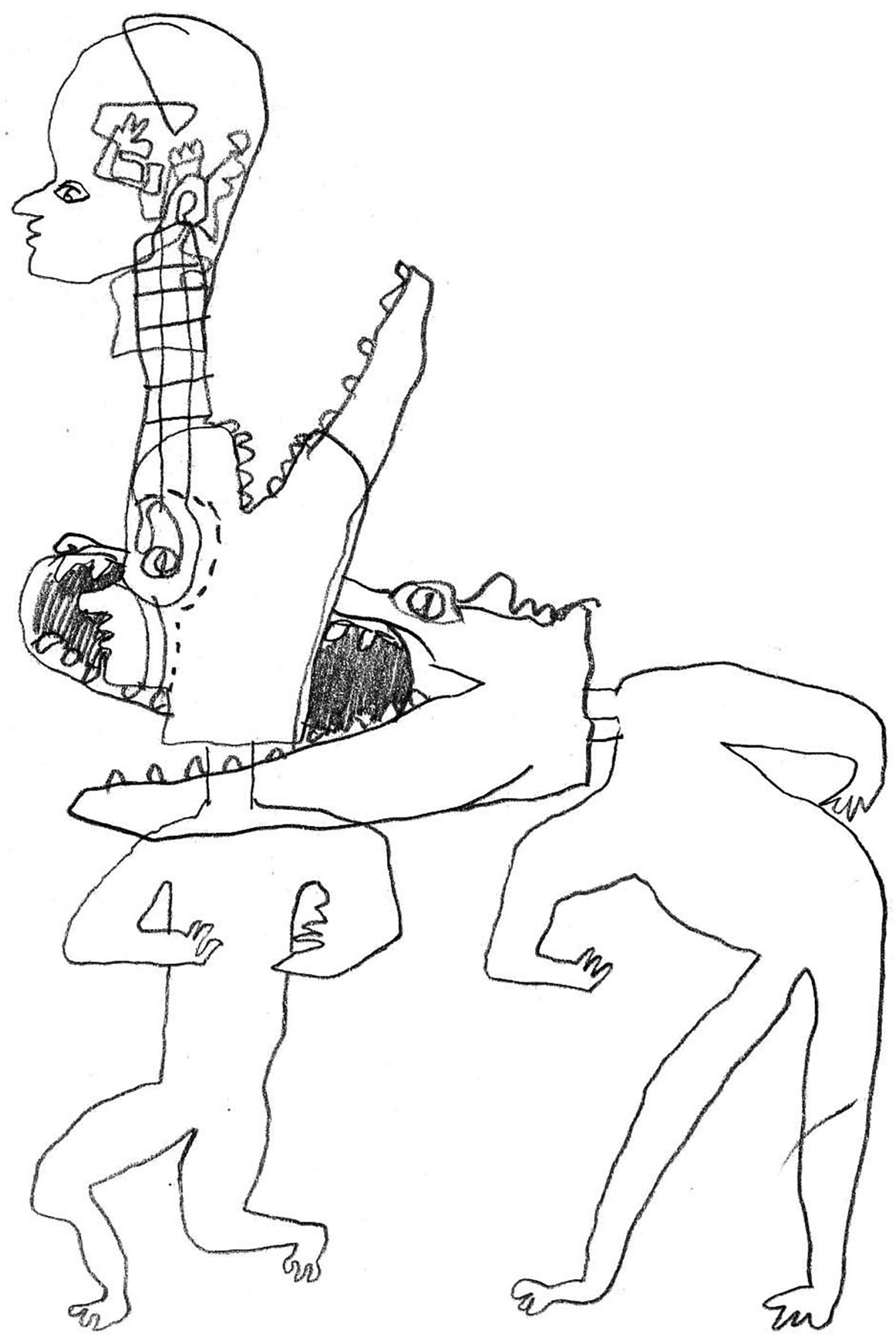

Cocodrilos mordiendo, de la serie Dibujo simple (2017). Lápiz: Carlos Alberto Badillo-Cruz. Prohibida su reproducción en obras derivadas. 